\title{
Análise do Uso de um Software Educacional no Ensino do Modelo de Oferta e Demanda
}

\author{
Use Analysis of an Educational Software in the \\ Teaching of the Supply and Demand Model
}

\author{
Romário da Silva Borges \\ Universidade Federal de Alfenas \\ Marcelo Lacerda Rezende \\ Universidade Federal de Alfenas
}

\begin{abstract}
Resumo: A inserção de tecnologias no ambiente educacional tem proporcionado recursos para dinamizar o ensino e torná-lo cada vez mais atrativo. A presente pesquisa teve como objetivo avaliar o uso de uma ferramenta educacional no ensino e aprendizagem de um conteúdo pertinente à microeconomia: o Modelo de Oferta e Demanda. Para isso, o software foi utilizado por um total de 75 indivíduos, sendo estes 65 alunos de graduação que cursam uma disciplina de introdução à Economia na Universidade Federal de Alfenas, e os outros 10 são pessoas de qualquer grau de ensino sem restrições prévias. Os participantes responderam um questionário contendo três seções, com o intuito de avaliar o aprendizado após o uso do software, a eficiência como material didático e questões técnicas de usabilidade. Como resultado, a utilização do software contribuiu no processo de ensino e aprendizagem do modelo de Oferta e Demanda.
\end{abstract}

Palavras-chave: Software Educacional. Oferta e Demanda. Aprendizagem.

\begin{abstract}
The insertion of technologies in the educational environment has provided resources to streamline teaching and make it increasingly attractive. The present research aim to evaluate the use of an educational tool in the teaching and learning of content relevant to the microeconomy: the Supply and Demand Model. For this, the software was used by a total of 75 individuals, being these 65 undergraduate students who attend a course of Introduction to Economics at the Federal University of Alfenas, and the other 10 are people of any educational level without previous restrictions. The participants answered a questionnaire containing three sections, in order to evaluate the learning after the use of the software, the efficiency as didactic material and technical usability issues. As a result, the use of software contributed to the teaching and learning process of the Supply and Demand model.
\end{abstract}

Keywords: Educational Software. Supply and Demand. Learning. 


\section{Introdução}

Os métodos de ensino e aprendizagem têm gerado constantes questões em meios educacionais. A relação como um conteúdo chega até o receptor estabelece um paradigma, sendo que o objetivo central é conseguir maximizar a transmissão/absorção do conhecimento. Surge, então, a necessidade da escolha de estratégias com várias e expressivas práticas sugeridas ao aluno, objetivando ultrapassar seus dados iniciais sobre o objeto do conhecimento (ANASTASIOU, 2004).

Nesse contexto, pode-se identificar um campo em ascensão: os sistemas computacionais educacionais, ferramentas desenvolvidas com o intuito de contribuir para o processo de ensino e aprendizagem (SILVA et al., 2014). Esses sistemas têm sido utilizados por educadores de todos os níveis de ensino, não se limitando a níveis específicos de instrução, nem à educação à distância ou presencial, mas envolvendo todos os campos educacionais e processos.

Um software educacional (SE) propicia ao estudante um ambiente de interação com a interface do programa tornando-o participante ativo no processo de aprendizagem. Para Rojas et al. (2008):

\footnotetext{
Um ambiente de aprendizagem interativo e cooperativo é aquele onde, além dos instrumentos interativos, os estudantes e os professores podem aprender, se informar, relacionar-se de várias formas, fazer pesquisas, evoluir junto no desenvolvimento de diversos projetos e trabalhos (p.16).
}

Dessa forma, uma proposta educacional que esteve, e está em muitos casos centrada no professor detentor do conhecimento, poderá nesse novo ambiente ocorrer com base nos processos de desenvolvimento de competências e habilidades do próprio aluno. Assim, o uso de recursos computacionais pode, como em outras áreas do conhecimento, beneficiar o ensino da Teoria Econômica. A economia é, como definido em ANGE (2006, p.8), "uma ciência social e, como tal, envolve relações humanas e influencia direta e indiretamente a vida das pessoas, o que torna fundamental sua base ética". Assim, a importância desse estudo é essencial para uma formação sólida e consciente do futuro profissional, o que faz com que conteúdos relacionados a Economia estejam presentes em cursos de diferentes áreas do conhecimento.

Apesar disso, o ensino de Economia para estudantes que não estão em um curso dessa área está associado a uma série de desafios. Os alunos podem ser muito diferentes em termos de suas origens acadêmicas e de habilidades, podendo estar interessados e conhecerem Economia, juntamente com outros que estão menos interessados e estão cursando a disciplina porque é obrigatória (ELLIOT; SLOMAN, 2016). Assim, há um alto nível de não envolvimento com o assunto. Isso leva a altas taxas de insucesso e evasão, além de uma experiência negativa tanto para os alunos quanto para o instrutor (DENNY, 2014).

Para evitar esses problemas, é necessário, além de definir os conteúdos que possam ser de maior interesse e utilidade para essa diversidade de estudantes, encontrar estratégias de ensino 
que estejam de acordo com suas habilidades e com os conhecimentos já adquiridos pelo grupo. Motivar esses estudantes e demonstrar a real necessidade de se ter um conhecimento básico de Economia é um desafio para o professor e determinante para o sucesso de uma disciplina voltada para não-economistas. Diante disso, com o intuito de contribuir no processo de ensino e aprendizagem, através de uma ferramenta educativa, a presente pesquisa tem como objetivo avaliar a utilização de um SE por estudantes de graduação. Espera-se, com essa avaliação, obter subsídios para o aperfeiçoamento do SE estudado e para o desenvolvimento de novos sistemas.

O software educacional utilizado trata sobre um assunto pertinente da microeconomia: o Modelo de Oferta e Demanda. A necessidade de tal estudo se aplica pelo fato da Teoria Econômica ser trabalhada com diferentes grupos de estudantes, das mais diversas áreas do conhecimento, principalmente por ser considerada em muitos projetos pedagógicos como uma disciplina de formação geral.

O público alvo dessa pesquisa são estudantes de graduação da Universidade Federal de Alfenas - dos cursos de Ciência da Computação, Geografia Bacharelado e Nutrição - que têm na grade curricular uma disciplina que aborda o Modelo de Oferta e Demanda. Todos os cursos são presenciais, porém na Computação a disciplina, é oferecida como EAD. Além disso, buscou-se também avaliar pessoas que não necessariamente estejam em cursos de graduação ou específicas da área, mas que por outro lado podem auxiliar na percepção da eficácia da ferramenta como meio pedagógico à distância.

\section{Embasamento Teórico}

\subsection{Ferramentas de Ensino}

A sociedade ao longo dos anos vem passando por diversos processos e mudanças na forma de comunicação, utilizando a tecnologia como um meio otimizador de atividades existentes. Assim, observa-se tal feito na educação, que por intermédio do arsenal de ferramentas propostas - telecomunicações, softwares e hardwares -, permite proporcionar uma nova experiência aos envolvidos.

As novas tecnologias estão associadas à interatividade e à quebra do modelo comunicacional um-todos, em que a informação é transmitida de modo unidirecional (VELLOSO, 2014, p.12). Assim, verifica-se que a inovação proposta pela tecnologia proporciona um fator fundamental para que o processo de ensino e aprendizagem seja capaz de atender a esse novo modelo educacional. As ferramentas de ensino consistem, de modo geral, em atividades estratégicas e até inovadoras que poderão oportunizar a redescoberta da espontaneidade, despertando o senso crítico do aluno e colocando, obrigatoriamente, o professor no papel mediador (LABROW, 2012). Dessa forma a utilização desses artifícios podem ter um papel importante em ambientes de caráter educacional.

Além do mais, o perfil dos estudantes - de modo amplo - se modificou juntamente com a ascensão das novas tecnologias, dado que no cotidiano deles o uso de aparatos eletrônicos se tornou constante. Diante dessa expansão digital, as sessões convencionais e tradicionais de 
ensino podem ser pouco suficientes para motivá-los ao estudo. Entretanto, o ensino apoiado pelo uso de dispositivos digitais tende a sobrepor as abordagens obsoletas (MASCHIO; DIRENE, 2015).

Portanto, a adaptação de um modelo ao meio tecnológico, apresenta-se como uma possível estratégia educacional eficaz. Quando se cria ou adapta um software ao conteúdo escolar, ocorrerá o desenvolvimento de aptidões que envolvem o indivíduo em todos os aspectos: cognitivos, emocionais e relacionais (BORGES; SCHWARZ, 2005).

Além disso, de acordo com Ramos (1996), a incorporação das Tecnologias de Informação e Comunicação (TIC) na educação perpassa também por questões econômicas, sociais e políticas. $\mathrm{Na}$ perspectiva pedagógica da alfabetização tecnológica, a autora ressalta o papel dessa alfabetização em níveis de compreensão do instrumento tecnológico e também no nível de compreensão sobre seu uso. Em outras palavras, esse letramento digital ou literacia digital propicia a aquisição da capacidade de avaliar, julgar o instrumento por suas funções para melhorar a si mesmo, ativando funções críticas autônomas. Muitas vezes, o estudante sabe manipular alguns recursos tecnológicos, todavia não detém de destreza para lidar com eles no contexto educacional. Para exemplificar: sabem navegar pela Internet, acessar seus perfis em sites de relacionamento, porém não têm a menor noção do que seja uma planilha eletrônica e suas funções. Daí a importância de se adquirir essa alfabetização.

No que diz respeito às questões econômicas, Ramos (1996) argumenta sobre a possibilidade do indivíduo ser capaz de consumir informação e notícias, além de se tornar apto para discernir o que lê, escreve ou publica. Sobre a questão social, a autora acrescenta que essa alfabetização tende a diminuir o distanciamento cultural entre as camadas abastadas e os excluídos. E em relação à questão política, ela pressupõe o caráter de massificação que está alfabetização informática pode proporcionar. Autores como Kenski (2008) interpretam essa perspectiva de informatização como democratização da educação, ao proporcionar oportunidades de aprendizado tecnológico a todos.

\subsection{Modelo de Oferta e Demanda}

A Economia - como ciência social - pode ser definida em três vertentes: análise da produção, distribuição e consumo de bens e serviços. Ademais, é responsável por estudar a atividade econômica, por intermédio da aplicação da teoria econômica. Seus modelos e técnicas usados atualmente evoluíram da economia política do final do século XIX, derivado da vontade de usar métodos mais empíricos à semelhança das ciências naturais (CLARK, 1998).

Constituindo-se de um corpo unitário de conhecimento da realidade, a Teoria Econômica - por razões didáticas - é estudada de forma segmentada. Uma das divisões mais frequentemente encontradas nos livros textos, segmenta a Teoria Econômica em: 1) Microeconomia (teoria dos preços); 2) Macroeconomia (equilíbrio da renda nacional); 3) Desenvolvimento Econômico; e 4) Economia Internacional (RIZZIERI, 2004; ROSSETTI, 2000). 
A Microeconomia dedica-se ao comportamento das unidades econômicas de modo individual, tais como consumidores, trabalhadores, investidores ou empresas. Em suma, essas unidades contemplam quaisquer indivíduos ou entidades que tenham participação no funcionamento da economia. Assim, a microeconomia explica como e porque essas unidades tomam decisões econômicas (VARIAN, 2006; PINDYCK e RUBINFELD, 2004).

O Modelo de Oferta e Demanda é um conceito primordial dentro do estudo da microeconomia, razão pela qual foi escolhido como tema do software proposto na presente pesquisa. A sua compreensão se baseia em dois conceitos chaves: a curva de demanda e a curva de oferta. Além disso, é preciso compreender o comportamento das diferentes variáveis que afetam essas curvas (efeitos do clima, avanço tecnológico, custo da mão de obra e etc).

A curva de demanda mostra as quantidades que os consumidores estão dispostos a adquirir de um bem, ou serviço, em função de seus preços. Nesse caso, considera-se constantes todas às demais variáveis que possam afetar a demanda. Quanto menor o preço de um bem, maior será a quantidade que o consumidor deseja adquirir. Portanto, existe uma relação inversa entre preço e quantidade desejada. Por sua vez, pode-se ter um aumento da demanda, ocasionando um deslocamento da sua curva, sem que ocorra uma variação no nível de preço. Esse deslocamento ocorre devido a mudanças em variáveis como a renda, os preços dos outros bens e o gosto ou preferência do consumidor. Assim, os principais determinantes da demanda de bem $x$ podem sere representados da seguinte forma (PINDYCK e RUBINFELD, 2004):

$D x=f(P x, P 1, P 2 \ldots P n-1, R, G)$

Sendo: $\mathrm{Dx}=$ demanda do bem $\mathrm{x}$;

$\mathrm{Px}=$ preço do bem $\mathrm{x}$;

$\mathrm{P} 1, \mathrm{P} 2 \ldots \mathrm{Pn}-1$ = preço dos outros bens;

$\mathrm{R}=$ renda; $\mathrm{e}$

$\mathrm{G}=$ gosto.

Dessa forma, o software foi desenvolvido no sentido de fazer com que os usuários sejam capazes de alterar essas variáveis e percebam, graficamente, o resultado desse movimento. Assim, espera-se que consigam compreender bem o comportamento da demanda. A mesma possibilidade de alteração das variáveis, com seus resultados sendo apresentados graficamente, será usada com a oferta.

Entretanto, essa curva relaciona as quantidades que os produtores estão dispostos a oferecer a determinado preço, permanecendo constante todas às demais variáveis que possam afetar a oferta. Considera-se que quanto maior o preço, maior será o desejo dos produtores em vender seu produto. Assim como na demanda, tem-se variáveis que são capazes de causar um aumento, ou redução, na quantidade ofertada. Pode-se então, descrever a curva de oferta como dependente principalmente das seguintes variáveis (PINDYCK e RUBINFELD, 2004):

$$
O x=f(P x, F 1, F 2 \ldots F n-1, P 1, P 2 \ldots P n-1, T)
$$


Sendo: $O x=$ oferta do bem $x$;

$\mathrm{Px}=$ preço do bem $\mathrm{x}$;

$\mathrm{F} 1, \mathrm{~F} 2 \ldots \mathrm{Fn}-1$ = preço dos fatores de produção;

$\mathrm{P} 1, \mathrm{P} 2 \ldots \mathrm{Pn}-1$ = preço dos outros bens; $\mathrm{e}$

$\mathrm{T}=$ tecnologia.

Por fim, a junção das curvas de oferta e demanda cria a situação denominada "Equilíbrio de Mercado", onde são utilizadas as variáveis explicitadas tanto na oferta quanto na demanda para a análise das interações entre essas variáveis no mercado. O equilíbrio de mercado também pode ser trabalhado na terceira seção do software examinado.

\section{Materiais e métodos}

\subsection{Software utilizado e ambiente de desenvolvimento}

Para a realização deste trabalho foi realizado o uso do software educacional desenvolvido no projeto de pesquisa da Universidade Federal de Alfenas "Desenvolvimento de um Software Auxiliar para o ensino do Modelo de Oferta e Demanda" (NABETO et al., 2015). Para esta pesquisa o SE passou por várias modificações com o intuito de promover uma melhoria na experiência do usuário. Dentre elas, foram alteradas as formas de acesso, criação de tutoriais e mudança em toda estrutura gráfica. O programa já conta com mais de mil acessos no período de 18 de agosto de 2015 a 10 de janeiro de 2019, conforme informação na página de acesso.

O ambiente de desenvolvimento utilizado foi o Scratch, que se trata de um projeto do grupo Lifelong Kindergarten do Media Lab do Massachusetts Institute of Technology (MIT). De modo geral, é uma linguagem de programação projetada, especificamente, para fins educacionais. Os softwares desenvolvidos nesse ambiente são gratuitos, de acordo com os termos da licença de uso Attribution-ShareAlike 2.0 Generic (CC BY-SA 2.0), disponível em https://scratch.mit.edu/terms of use, podendo ser acessado em https://scratch.mit.edu/projects/73378962/.

A escolha dessa linguagem de programação se deve às características fundamentais como: alta usabilidade, que representa a facilidade com que as pessoas podem empregá-la a fim de realizar uma tarefa específica; portabilidade simplificada, podendo ser usado em qualquer sistema operacional de um computador; e simples modo de compartilhamento de projetos, que é a capacidade de disponibilizar e atualizar um software. "Embora o principal enfoque do uso educacional do ambiente Scratch seja o desenvolvimento de programas pelos próprios alunos, também pode ser utilizado para a elaboração de objetos de aprendizagem (OA), que visam apoiar a construção do conhecimento" (BATISTA e BAPTISTA, 2013). Esses OA podem ser criados em qualquer tipo de mídia ou formato e ser simples, como uma animação ou uma apresentação de slides, ou até complexos, como uma simulação (MACÊDO et al., 2007).

Além disso, os OAs são recursos digitais importantes para o processo de ensino aprendizagem, criando um ambiente de aprendizado rico e flexível (Silva et al., 2016). Sendo assim Spinelli $(2007$, p.7) define os OAs como: 
"...um recurso digital reutilizável que auxilia na aprendizagem de algum conceito e, ao mesmo tempo, estimula o desenvolvimento de capacidades pessoais, como por exemplo, imaginação e criatividade. Dessa forma, um objeto virtual de aprendizagem pode tanto contemplar um único conceito quanto englobar todo o corpo de uma teoria. Pode ainda compor um percurso didático, envolvendo um conjunto de atividades, focalizando apenas determinado aspecto do conteúdo envolvido, ou formando, com exclusividade, a metodologia adotada para determinado trabalho."

\subsection{Conteúdo abordado}

O software utilizado trata sobre o Modelo de Oferta e Demanda sendo que, para estudá-lo, é preciso compreender os conceitos iniciais e a definição desse modelo. Após isso será possível dedicar-se ao estudo do Equilíbrio de Mercado.

O software é dividido em três seções. Na primeira, a curva de demanda relaciona as quantidades que os consumidores estão dispostos a adquirir de um bem, ou serviço, em função de seus preços. Já a curva da oferta, segunda seção, relaciona as quantidades que os produtores estão dispostos a oferecer a determinado preço, permanecendo constante todas as demais variáveis que possam afetar a oferta. Por fim, na terceira seção, o usuário poderá trabalhar com as duas curvas - oferta e demanda - de modo simultâneo, dentro do que é conhecido por "Equilíbrio de Mercado", utilizando as mesmas variáveis propostas na Oferta e Demanda.

Dessa forma, o software tem como objetivo fazer com que os usuários sejam capazes de alterar essas variáveis e percebam, graficamente, o resultado desse movimento. Na Figura 1 é possível ver os principais passos de execução do software. O ambiente contou também com tutoriais, sendo eles disponíveis em tempo de execução e antes de utilizar o programa, o que é possível observar na Figura 2.

Figura 1 - Passos de execução do software ao escolher a opção "Equilíbrio de Mercado"

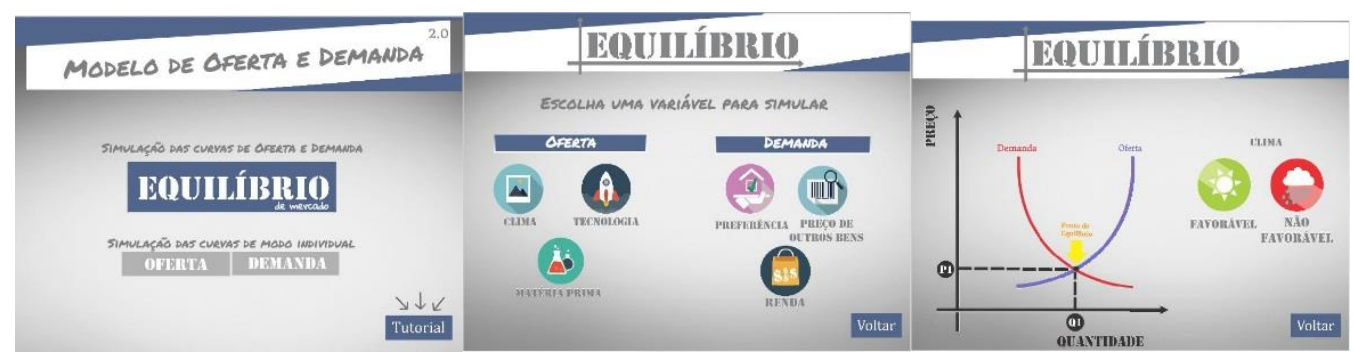




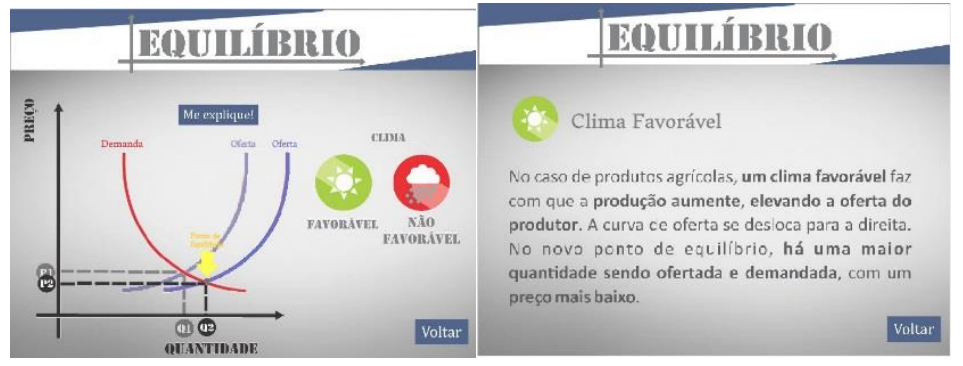

Fonte: Software Educacional pesquisado.

Em (1) escolha dos conceitos; (2) tela com as variáveis; (3) gráfico sem a alteração da variável; (4) gráfico após a variável escolhida sofrer alteração; (5) explicação da movimentação da curva.

Figura 2 - Telas do software pesquisado.

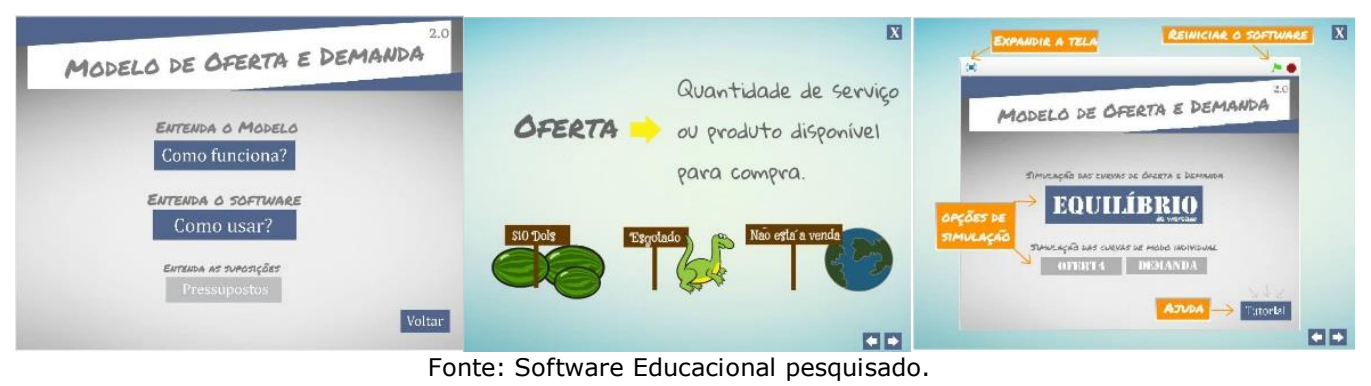

Em (1) tela de tutoriais; (2) explicação dos conceitos; (3) como usar o software.

\subsection{Sistematização e obtenção dos dados}

A avaliação contou com um total de 75 participantes, sendo este dividido em dois grupos: 0 grupo 1 ( 65 pessoas) é constituído por alunos de graduação da Unifal-MG - que cursam disciplinas de Introdução à Economia, dos cursos de Nutrição, Bacharelado em Geografia e Bacharelado em Ciência da Computação; o grupo 2 (10 pessoas) contempla indivíduos de qualquer grau de escolaridade e que não tenham - necessariamente - conhecimentos prévios sobre o assunto. Para compor esse grupo, foi criado um vídeo no Youtube (https://www.youtube.com/watch?v=7YJMgbYbKO8) explicando resumidamente os conceitos do modelo por meio da utilização do software. Na parte final do vídeo, foi solicitado aos usuários que respondessem ao questionário. No fim de um mês, obteve-se os 10 questionários respondidos. Todas as atividades do grupo 2 não ocorreram presencialmente.

A criação de dois grupos, deu-se pela proposta de avaliação. O primeiro grupo utiliza o SE como um artifício complementar da aula. Já o segundo grupo o utiliza como ferramenta exclusiva de aprendizagem. É importante ressaltar que, os alunos de Ciência da Computação, apesar de cursarem a disciplina em EAD, têm acesso a um ambiente online exclusivo para a disciplina, por isso foram alocados no grupo 1. Assim, espera-se avaliar a ferramenta como sendo um complemento de ensino ao professor e, ao mesmo tempo, avaliar os potenciais de aprendizagem por meio dela à distância. 
Os alunos de Nutrição e Geografia contaram com uma aula presencial sobre os conceitos abordados e sobre a ferramenta. Os estudantes da Computação, que cursaram a disciplina em EAD, foram direcionados para o site do SE após a aula sobre o assunto. Esse primeiro grupo também teve acesso ao vídeo sobre a utilização do software.

A avaliação se deu por intermédio de um questionário dividido em três seções, que só foram respondidos após a utilização do SE. A primeira contou com perguntas sobre o assunto. A segunda buscou averiguar o grau de conhecimento do participante sobre o assunto e se houve evolução após o uso do SE. E a terceira, pretendia medir a experiência de usabilidade do usuário. Para o segundo e terceiro questionários, os participantes responderam utilizando uma métrica, dando notas de 1 a 5 (1 - Muito baixa, 2 - Baixa, 3 - Neutra, 4 - Alta, 5 - Muito alta).

Para a avaliação do SE tomou-se diretrizes específicas propostas por Fantin (2017). Para essa autora é necessário considerar características técnicas, funcionais e didáticas quando se avalia softwares educacionais, a fim de tornar sua avaliação mais abrangente. Essas características podem ser representadas pelos tópicos seguintes, utilizados no presente trabalho: Facilidade de aprendizagem; Flexibilidade e eficiência; Prevenção de erros; Ajuda e documentação; Satisfação, Adequação pedagógica; Utilidade e Adequação técnica.

\section{Resultados e discussão}

O questionário foi dividido em três seções: na primeira as perguntas se diferenciaram entre os grupos da pesquisa. Para o grupo 1 (Alunos cursando a disciplina de Introdução a Economia) houve questões totalmente práticas, com o intuito de avaliar se os alunos sabiam utilizar o cohecimento adquirido pela teoria em situações reais, como por exemplo: "Considerando que manteiga e margarina são bens substitutos, qual seria o efeito de uma redução no preço da margarina sobre a quantidade demandada de manteiga?".

Já para o grupo 2 (participantes independentes), foram mescladas práticas e teóricas, sendo as teóricas relacionadas com os fundamentos do conteúdo a ser avaliado, como: "Se um produto está sendo muito ofertado, ou seja, uma quantidade grande desse produto está sendo oferecido, porém a sua demanda está baixa. Pelo Modelo de Oferta e Demanda, o que deve acontecer com o Preço do produto?". Tal diferenciação se deve ao fato que os integrantes do grupo 2 não estão envolvidos diretamente com o conteúdo abordado e por terem utilizado a ferramenta sem o auxílio de um instrutor.

Para a avaliação presencial, o professor responsável pela disciplina apresentou o software em sala de aula, podendo os discentes questionar caso houvessem alguma dúvida relacionada ao seu uso. Para a avaliação à distância, de modo opcional, os participantes poderiam assistir um vídeo disponibilizado no sitio web youtube (https://www. youtube.com/watch?v=7YJMgbYbKO8\&t=3s) contendo informações sobre 0 funcionamento da ferramenta.

Assim, com o intuito de avaliar o índice de acertos sobre o conteúdo apresentado, o grupo 1 obteve $81,5 \%$ de respostas corretas, enquanto o grupo 2 obteve $82,5 \%$, como apresentado na 
Figura 3 (1). É evidente a proximidade entre os dois grupos, alcançando, em ambos, um índice acima de $80 \%$, evidenciando um bom rendimento dos participantes.

Na segunda seção os grupos também foram avaliados separadamente. Para o grupo 1 buscouse avaliar questões sobre a aula como um todo. Quando questionado sobre a importância que o conteúdo tem na formação cidadã e acadêmica, 87,7\% consideram muito importante. Com relação à dificuldade de aprendizado, aproximadamente $50 \%$ dos alunos consideram o assunto como mediano, $40 \%$ o consideram fácil e $10 \%$ difícil.

Foi avaliado também, o quanto eles consideravam seu domínio antes do uso do software, e o quanto evoluíram após a aula como um todo (SE em complemento à aula). Antes do uso, 27,3\% sentiam-se dominantes sobre o assunto. Após o uso, 75\% se consideraram dominantes.

Para o grupo 2, foi avaliado apenas o quanto eles consideravam seu conhecimento sobre o assunto antes do uso do SE, e como consideraram a evolução que tiveram após o seu uso. Nesse caso, obteve-se que antes de utilizarem a ferramenta, apenas $20 \%$ consideravam ter um bom entendimento, e após a utilização, 80\% consideraram ter bom domínio.

Figura 3 - Resultado dos questionários

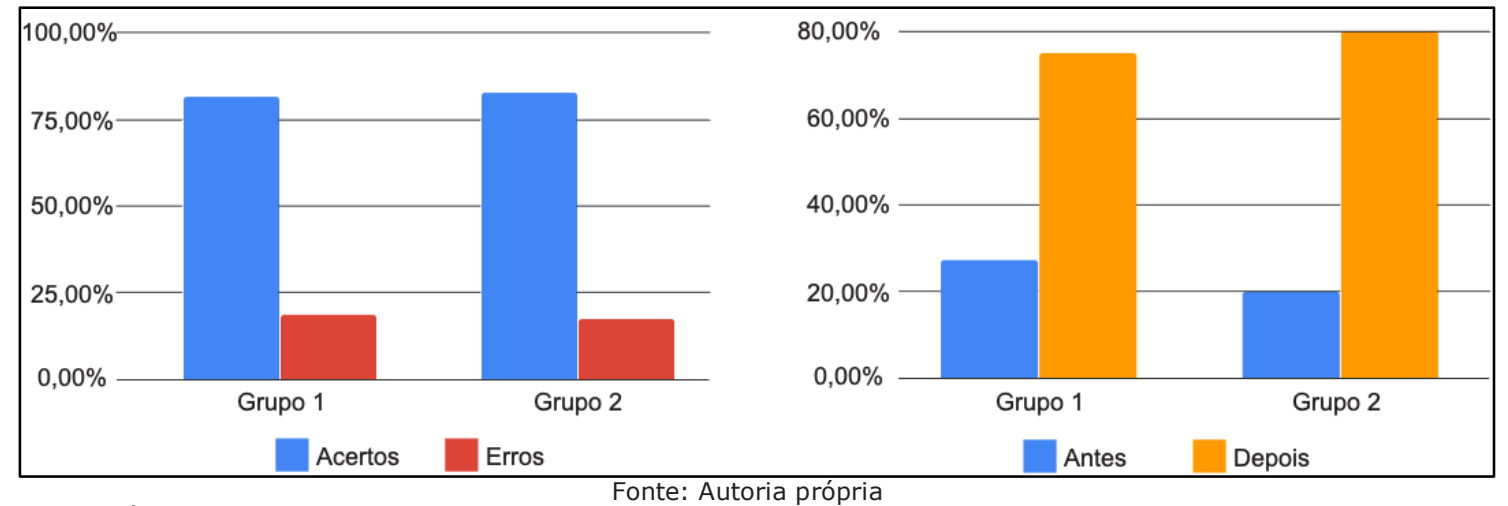

Em (1) Índice de erros e acertos nas questões sobre o Modelo de Oferta e Demanda; (2) Evolução na aprendizagem antes e após o uso do Software Educacional

A terceira seção teve como objetivo avaliar a experiência do usuário ao utilizar o SE. Assim, utilizou-se do padrão mencionado anteriormente e obtiveram-se os resultados apresentados na Tabela 1. Também se buscou avaliar a experiência gráfica.

Com base na Tabela 1, observa-se uma avaliação satisfatória pelos participantes, entretanto é possível avaliar que há pontos a serem melhorados, principalmente no que diz respeito à facilidade de aprendizagem. De acordo com os respondentes, "o software é bastante intuitivo e com aparência agradável" e "as explicações foram montadas de maneira muito visual, o que facilita o entendimento do conteúdo" (Trecho extraído de uma das respostas ao questionário). Um deles sugeriu apenas melhorar a explicação das curvas gráficas, pois "foi a parte que levei um tempo maior para entender, em comparação com o restante do conteúdo" (Trecho extraído de uma das respostas ao questionário). E quando questionados se utilizariam o software para 
eventuais estudos sobre o assunto novamente, 89,2\% dos participantes do grupo 1 afirmaram positivamente.

Além disso, tendo como base os dados de avaliação da Tabela 1, pode-se considerar que a utilização do Scratch como plataforma de desenvolvimento foi suficiente para alcançar um resultado positivo.

Tabela 1 - Experiência de usabilidade do usuário

\begin{tabular}{|l|l|l|}
\hline \multicolumn{1}{|c|}{$\begin{array}{c}\text { Metas } \\
\text { Específicas }\end{array}$} & \multicolumn{1}{|c|}{ Grupo 1 } & \multicolumn{1}{|c|}{ Grupo 2 } \\
\hline $\begin{array}{l}\text { Facilidade de } \\
\text { Aprendizagem }\end{array}$ & $\begin{array}{l}\text { 64,1\% consideraram um tempo de } \\
\text { aprendizagem rápido e 32,8\% disseram } \\
\text { ser mediano. }\end{array}$ & $\begin{array}{l}70 \% \text { consideraram um tempo de } \\
\text { aprendizagem rápido e 20\% disseram } \\
\text { ser mediano. }\end{array}$ \\
\hline $\begin{array}{l}\text { Flexibilidade eficiência; ajuda e } \\
\text { documentação }\end{array}$ & $\begin{array}{l}87,7 \text { \% afirmaram que o software } \\
\text { necessárias para utilizá-lo informações }\end{array}$ & $\begin{array}{l}80 \% \text { afirmaram que o software oferece } \\
\text { todas as informações necessárias para } \\
\text { utilizá-lo }\end{array}$ \\
\hline $\begin{array}{l}\text { Prevenção de erro; } \\
\text { Adequação } \\
\text { técnica }\end{array}$ & $\begin{array}{l}84,3 \% \text { relataram ter boa experiência } \\
\text { de uso (tempo de execução das tarefas } \\
\text { são aceitáveis e falhas durante a } \\
\text { execução são baixos) }\end{array}$ & $\begin{array}{l}\text { uso (tempo de execução das tarefas são } \\
\text { uceitán e falhas durante a execução } \\
\text { são baixos) }\end{array}$ \\
\hline $\begin{array}{l}\text { Adequação } \\
\text { pedagógica }\end{array}$ & $\begin{array}{l}95,4 \% \text { consideram que o software } \\
\text { cumpriu com o que era proposto } \\
\text { (Apresentou correspondência com o } \\
\text { conteúdo abordado) }\end{array}$ & $\begin{array}{l}90 \text { cumpriu com o que era proposto } \\
\text { (Apresentou correspondência com o } \\
\text { conteúdo abordado) }\end{array}$ \\
\hline Recursos gráficos & $\begin{array}{l}86,2 \% \text { relataram que o software possui } \\
\text { uma boa comunicação visual }\end{array}$ & $\begin{array}{l}90 \% \text { relataram que o software possui } \\
\text { uma boa comunicação visual }\end{array}$ \\
\hline
\end{tabular}

Fonte: Autoria própria.

\section{Conclusões}

De modo geral, através da investigação proposta, o SE Modelo de Oferta e Demanda demonstrou resultados positivos e eficazes no ensino e aprendizagem do modelo econômico. É importante salientar que os níveis de acertos e de satisfação são bem similares entre os dois grupos, não havendo dados muitos discrepantes entre eles. O que mostra a potencialidade do software em atuar tanto como material de apoio ao professor quanto possuir caráter suficiente para a autoaprendizagem ou à distância.

Por fim, a presente pesquisa propôs trazer resultados de uma proposta de um ambiente computacional que pôde potencializar a representação gráfica sobre o Modelo de Oferta e Demanda. Assim, futuros trabalhos podem utilizar como referência a estrutura metodológica de aplicação, avaliação do software proposto e a construção de novas ferramentas que trabalhem conceitos correlacionados. E aos professores uma forma de incentivo à inserção de ferramentas que facilitem a transmissão de um determinado assunto, sendo uma alternativa - ou um complemento - ao método tradicional de ensino. 


\section{REFERÊNCIAS BIBLIOGRÁFICAS}

ANASTASIOU, L. G. C.; ALVES, L. P. Processo de ensinagem na universidade: pressupostos para as estratégias de trabalho em aula. Joinville: Universille, 2004.

ASSOCIAÇÃO NACIONAL DE CURSOS DE GRADUAÇÃO EM CIÊNCIAS ECONÔMICAS ANGE. Orientação acadêmica, 2006. Novas Diretrizes dos Cursos de Ciências Econômicas. Associação Nacional dos Cursos de Graduação em Economia.Disponível em: http://www.ange.org.br/site/wpcontent/uploads/2016/02/Cadernos ANGE 2010 diretrizes.pdf. Acesso em: 16 set. 2019.

BATISTA, S. C. F.; BAPTISTA, C. B. F. SCRATCH E MATEMÁTICA: DESENVOLVIMENTO DE UM OBJETO DE APRENDIZAGEM. 2013. 8 p. $1^{\circ}$ Encontro de Educação Matemática (Matemática)Instituto Federal de Educação, Ciência e Tecnologia Fluminense, [S.I.], 2015. Disponível em: $<$ http://www.essentiaeditora.iff.edu.br/index.php/encontrodematematica/article/view/4877>. Acesso em: 03 jan. 2019.

BORGES, R.M.R.; SCHWARZ, V.O. O Papel dos jogos educativos no processo de qualificação de professores de ciências. In: ENCONTRO IBERO-AMERICANO DE COLETIVOS ESCOLARES E REDES DE PROFESSORES QUE FAZEM INVESTIGAÇÃO NA ESCOLA, 4. Lajeado, 2005.

CLARK, B. Political-economy: A comparative approach. Westport, CT: Preager, 1998.

DALFOVO, M. S., LANA, R. A., SILVEIRA, A. Métodos quantitativos e qualitativos: um resgate teórico. Revista Interdisciplinar Científica Aplicada, Blumenau, v. 2, n. 4, p. 01-13, 2008.

DENNY, E. Factors influencing the performance of non-economics majors in an introductory economics course. International Review of Economics Education, v.17, p.1-16, 2014.

ELLIOTT, C.; SLOMAN, J. Teaching Economics to Non Economics Majors. Internet site: <https://www.economicsnetwork.ac.uk/themes/nonspecialists > Access: June, 23, 2016.

FANTIN, K. - Metodologia de Avaliação de Software Educacional. Disponível em: <https://repositorio.ucs.br/handle/11338/3080 >. Acesso em: 25 novembro 2018.

KENSKI, V. M.. Tecnologias e Ensino Presencial e a Distância. 5ed. Campinas: Papirus, 2003.

LABROW, M. Atividades criativas para a sala de aula. 2. ed. Petrópolis: Vozes, 2011.

MACÊDO, L. N. de; CASTRO FILHO, J. A. de; MACÊDO, A. A. M.; SIQUEIRA, D. M. B.; OLIVEIRA, E. M. de; SALES, G. L.; FREIRE, R. S. Desenvolvendo o pensamento proporcional com o uso de um objeto de aprendizagem. In: PRATA, C. L.; NASCIMENTO, A. C. A de (Org.). Objetos de aprendizagem: uma proposta de recurso pedagógico. Brasília: MEC, SEED, 2007. p. 17-26.

MASCHIO, E.; DIRENE, A. I. Múltiplas Representações Externas no Suporte à Aquisição de Conhecimento em Programação de Computadores. Revista Brasileira de Informática na Educação, v. 23, n. 3, 2015.

NABETO, L. O.; AVILA, A. A.; OliVEIRA, H. A.; BORGES, R. S.; REZENDE, M. L. Desenvolvimento de um software auxiliar para o ensino do Modelo de Oferta e Demanda. 2015. (Apresentação de Trabalho/Simpósio).

PINDYCK, R. S.; RUBINFELD, D. L. Microeconomia. 5 Ed. São Paulo: Prentice Hall, 2004. 
RAMOS, E. M. F. Educação e informática: reflexões básicas. Educação e informática: reflexões básicas, 1996. Cidade e Casa editora

RIZZIERI, J. A. B. Introdução à economia. IN: Pinho, D. B., Vasconcellos, M. A. S. de Manual de economia: equipe de professores da USP. 5a ed. São Paulo: Saraiva, 2004.

ROJAS, A., RITTO, A.C.A., BARBOSA, A. C. C. O software livre para o ensino da matemática em instituições de ensino superior - uma tecnologia social. Cadernos do IME: Série Informática, v.25, p. 15-26, 2008.

ROSSETTI, J. P. Introdução à economia. 18ª ed. São Paulo: Atlas, 2000.

SCRATCH. - Modelo de Oferta e Demanda. Disponível em: <https://scratch.mit.edu/projects/73378962/\#player>. Acesso em: 25 novembro 2018.

SILVA, T. R.; LEMOS, B. M.; CARVALHO, C. V. A. Um software educacional para o apoio ao ensino de frações utilizando realidade aumentada. Acta Scientiae \&amp; Technicae, [S.I.], v. 2, n. 2, jan. 2015. ISSN 2317-8957. Ano? Número?

SILVA, E. K. S; da; FIGUeIREDO, L. V. de; SILVA, E. L. da. Banco internacional de objetos educacionais: caracterização dos objetos virtuais de aprendizagem disponibilizados para docência em química analítica. Revista de Pesquisa Interdisciplinar, Cajazeiras, v. 1, Ed. Especial, 191 - 201, set/dez. de 2016.

SPINELLI, W. Os objetos virtuais de aprendizagem: ação, criação e conhecimento. 2007. Disponível em: <http://rived.mec.gov.br/comousar/textoscomplementares/textoImodulo5.pdf >. Acesso em: 05 mai 2018.

VARIAN, H. R. Microeconomia: princípios básicos. 7a ed. Rio de janeiro: Elsevier, 2006.

VELLOSO, Fernando. (2014). Informática: Conceitos básicos. 9. ed. Rio de Janeiro: Elsevier.

YOUTUBE. - Software Oferta e demanda. Disponível em: $<$ https://www.youtube.com/watch?v=7YJMgbYbKO8>. Acesso em: 01 dezembro 2018.

Recebido em maio de 2019.

Aprovado para publicação em setembro de 2019.

\section{Romário da Silva Borges}

Departamento de Ciência da Computação - Universidade Federal de Alfenas - UNIFAL-MG, Brasil, romario.borges@bcc.unifal-mg.edu.br

\section{Marcelo Lacerda Rezende}

Programa de Pós-Graduação em Economia - Departamento de Ciência da Computação - Universidade Federal de Alfenas - UNIFAL-MG, Brasil, marcelo.rezende@unifal-mg.edu.br 